\title{
Cell-instructive high-resolution micropatterned polylactic acid surfaces
}

Citation for published version (APA):

Barata, D., Dias, P., Wieringa, P., van Blitterswijk, C., \& Habibovic, P. (2017). Cell-instructive highresolution micropatterned polylactic acid surfaces. Biofabrication, 9(3), [035004]. https://doi.org/10.1088/1758-5090/aa7d24

Document status and date:

Published: 01/09/2017

DOI:

10.1088/1758-5090/aa7d24

Document Version:

Publisher's PDF, also known as Version of record

Document license:

Taverne

Please check the document version of this publication:

- A submitted manuscript is the version of the article upon submission and before peer-review. There can be important differences between the submitted version and the official published version of record.

People interested in the research are advised to contact the author for the final version of the publication, or visit the DOI to the publisher's website.

- The final author version and the galley proof are versions of the publication after peer review.

- The final published version features the final layout of the paper including the volume, issue and page numbers.

Link to publication

\footnotetext{
General rights rights.

- You may freely distribute the URL identifying the publication in the public portal. please follow below link for the End User Agreement:

www.umlib.nl/taverne-license

Take down policy

If you believe that this document breaches copyright please contact us at:

repository@maastrichtuniversity.nl

providing details and we will investigate your claim.
}

Copyright and moral rights for the publications made accessible in the public portal are retained by the authors and/or other copyright owners and it is a condition of accessing publications that users recognise and abide by the legal requirements associated with these

- Users may download and print one copy of any publication from the public portal for the purpose of private study or research.

- You may not further distribute the material or use it for any profit-making activity or commercial gain

If the publication is distributed under the terms of Article $25 \mathrm{fa}$ of the Dutch Copyright Act, indicated by the "Taverne" license above, 
PAPER

\section{Cell-instructive high-resolution micropatterned polylactic acid surfaces}

To cite this article: David Barata et al 2017 Biofabrication 9035004

View the article online for updates and enhancements.

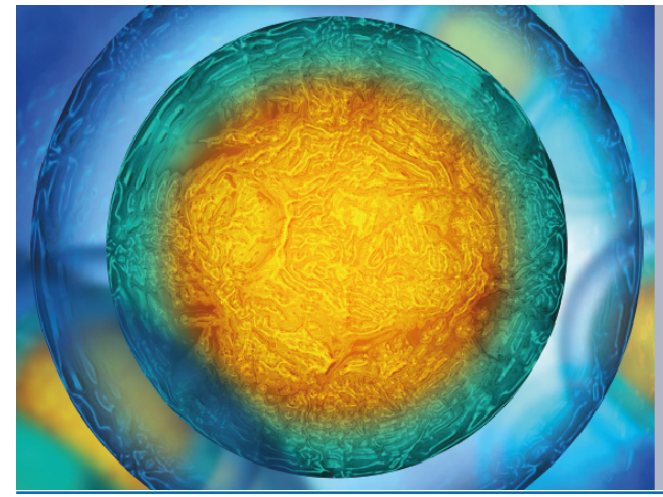

Biophysical Society $\quad$ IOP | ebookS

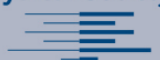
Recent citations
- Topographical patterning: characteristics of current processing techniques. controllable effects on material properties and co-cultured cell fate, updated applications in tissue engineering, and improvement strategies Ke Zhang et al
- PEG-based cross-linked films with aligned channels: combining cryogenic processing and photopolymerization for the design of micro-patterned oriented platforms Nancy M. Cativa et al
- Surface Modification of 3D Printed Polycaprolactone Constructs via a Solvent Treatment: Impact on Physical and Osteogenic Properties Alicja Kosik-Kozio et al

Alicja Kosik-Kozio etal 


\title{
Biofabrication
}

\section{PAPER}

CrossMark

\section{RECEIVED}

30 December 2016

REVISED

15 June 2017

ACCEPTED FOR PUBLICATION

3 July 2017

PUBLISHED

24 July 2017

\section{Cell-instructive high-resolution micropatterned polylactic acid} surfaces

\author{
David Barata $^{1,2}(\infty)$, Paulo Dias ${ }^{1}$, Paul Wieringa ${ }^{3}$, Clemens van Blitterswijk ${ }^{1,3}$ and Pamela Habibovic ${ }^{1,2}$ \\ 1 Department of Tissue Regeneration, MIRA Institute for Biomedical Technology and Technical Medicine, University of Twente, \\ Enschede, Overijssel, Netherlands \\ 2 Department of Instructive Biomaterials Engineering, MERLN Institute for Technology-Inspired Regenerative Medicine, Maastricht \\ University, Maastricht, Limburg, Netherlands \\ 3 Department of Complex Tissue Regeneration, MERLN Institute for Technology-Inspired Regenerative Medicine, Maastricht University, \\ Maastricht, Limburg, Netherlands \\ E-mail:p.habibovic@maastrichtuniversity.nl
}

Keywords: micropatterning, polylactic acid, cell adhesion, two-photon polymerization, topographies, cytoskeleton

Supplementary material for this article is available online

\begin{abstract}
Micro and nanoscale topographical structuring of biomaterial surfaces has been a valuable tool for influencing cell behavior, including cell attachment, proliferation and differentiation. However, most fabrication techniques for surface patterning of implantable biomaterials suffer from a limited resolution, not allowing controlled generation of sub-cellular three-dimensional features. Here, a direct laser lithography technique based on two-photon absorption was used to construct several patterns varying in size between $500 \mathrm{~nm}$ and $15 \mu \mathrm{m}$. Through replication via an intermediate mold, the patterns were transferred into polylactic acid (PLA), a widely used biomedical polymer, while retaining the original geometry. An osteoblast-like cell line, MG-63 was used for characterizing the morphological response to the topographical patterns. The results indicated that semi-continuous (dashed) lines, with a height of $1 \mu \mathrm{m}$ were able to induce cell elongation in the direction of the lines. However, when dashes with a height of $0.5 \mu \mathrm{m}$ were combined with perpendicularly crossing continuous lines (rails) with a height of $8 \mu \mathrm{m}$, the contact guidance effect of the dashes was lost and elongation of the cells was observed in the direction of the larger features. A second pattern, consisting of different arrays of pillars showed that, depending on the pillar height, the cells were either able to spread over the pattern or were confined between the pattern features. These differences in the ability of cells to spread further resulted in the formation of tension forces through stress fibers and displacement of vimentin. The method for high-resolution micropatterning of PLA as presented here can also be applied to other biomedical polymers, making it useful both for fundamental studies and for designing new biomaterials with improved functionality.
\end{abstract}

\section{Introduction}

In the human body, a number of tissues possess an intrinsic, albeit limited, ability to self-regenerate in the event of injury [1, 2]. Mechanisms governed by the immune system, blood coagulation cascade, and inflammatory pathways coordinate processes aimed to initiate recovery and ensure homeostasis restoration, addressing thereby cell proliferation, migration and differentiation.

Nevertheless, assisted regeneration can provide added value and is, in cases of severe injuries, even crucial to enhance clinical recovery. While regenerative medicine is a highly multidisciplinary field, employing different strategies that range from cell therapy to tissue engineering, the importance of synthetic biomaterials in this context is growing, owing to their unlimited availability and relatively low cost. Biomaterials have proven ability to create the microenvironments that may reconstitute physiological conditions, namely the extracellular matrix (ECM) [3, 4]. As such, biomaterials can provide the required mechanical and chemical cues, as well as other regulatory signaling important for cell self-renewal or commitment to a differentiation lineage $[3,5]$. 
Commonly applied techniques for fabricating biomaterials for regenerative strategies, such as freezedrying, cross-linking, electro-/wet-spinning, phase separation, etc $[6,7]$ revolve around the control over bulk properties such as chemical composition, mechanical strength and porosity. When surface properties are considered, roughness is a commonly varied parameter $[8,9]$. However, an increasing need exists for the techniques that allow controlled building of complex architectures, while optimizing their properties at different length scales. This has given rise to development of alternative additive manufacturing techniques, such as 3D printing (e.g. fused deposition modeling), laser ablation, stereolithography, micromolding and UV-lithography [10, 11$]$.

Nevertheless, resolution limitations of these techniques often restrict the level of accuracy to which the construct is able to mimic the natural in vivo environment. In response to this, efforts have been invested in hybrid strategies. For example, hierarchical 3D scaffolds were produced by direct writing electrospinning of fibers with multi-scale architecture [12]. In another study, surface of 3D scaffolds produced using 3D fused deposition were plasma-etched to control surface roughness [13]. Similarly, electrospinning was combined with nanolithography to provide the surface of electrospun fibers with nanoscale topographical features [14].

Micro and nanoscale topographical features on biomaterial surfaces have been shown a powerful tool for controlling the biological response to the biomaterials and currently, such features are often incorporated into synthetic biomaterials used for tissue or organ regeneration [15-18]. For example, nanoscale surface patterns have been shown to play a role in instructing stem cell niches fate in absence of additional biochemical signals, through direct effects of cell adhesion complexes on integrin receptors [19]. Furthermore, many examples exist in the literature that report on the relevance of micro and nanoscale topographical patterns in osteogenic [20, 21], adipogenic [21, 22], chondrogenic [23, 24], and neuronal differentiation [17, 25, 26], among others. Continuing the efforts to micro and nanostructure biomaterials and to study the effects of the topographical features on biological processes is justified in order to develop new instructive synthetic materials for regenerative medicine.

Recently, new developments have made two-photon polymerization (2PP) a viable option for structuring biomaterials with topographical features often in the range of few hundred nanometers [27, 28], which is determined by the voxel size. This technique allows direct laser-based rapid prototyping of custom-made 3D CAD designs with very high-resolution, often at sub-micrometer scale [29, 30], including features as small as $65 \mathrm{~nm}$ [31]. Being a direct laser writing technique, $2 \mathrm{PP}$ allows for generation of the topographical features with different heights within the same process step, in contrast to conventional photolithography techniques. Although not yet a realistic approach for production of bulk implantable materials, $2 \mathrm{PP}$ can be a useful research tool for creating structures with subcellular dimensions that directly interact with the cell and its organelles. 2PP has already been shown suitable for structuring of a range of polymers, including biocompatible polymers [32] and hydrogels [33, 34]. This enables the study of the interplay between micro- and nano-sized features, material chemistry and degradability. Therefore, 2PP offers new tools for a better understanding of fundamental cellular phenomena such as migration, mechanotransduction, force sensing, and tissue growth. Nevertheless, an important disadvantage of $2 \mathrm{PP}$ is that it is only suitable for photopolymerizable polymers and that it is associated with long processing time, and therefore, low throughput.

To overcome these limitations, in the current work, we have used $2 \mathrm{PP}$ to produce master $3 \mathrm{D}$ microstructures on the sub-cellular scale of a few micrometers. Then, micromolding was used as an enabling solution to produce a large number of high-definition replicas of the master structures in a clinically relevant biomedical polymer, polylactic acid (PLA). Micromolding was previously shown useful in replicating nano and micropatterned surfaces and structures [35-38], including 2PP-generated ones [27, 39]. The use of high-resolution 2PP microstructuring in combination with micromolding enabled to provide PLA with finely defined structural features, without the need for chemical modification of the polymer. Furthermore, the relatively simple method of micromolding by hot embossing allowed micropatterned areas to be replicated within minutes from a high-resolution master mold. As such, this method is also suitable for other thermoplastic polymers that are widely used in biomedical applications. In the current study, 3D micropatterned PLA surfaces produced using this two-step approach, i.e. via $2 \mathrm{PP}$ and micromolding, were used to study the response of osteoblast-like cell line MG-63 to multi-scale topographical surface features. (Figures 1(A), (B).)

\section{Materials and methods}

\subsection{Materials}

Photocrosslinkable resin IP-L 780 (Nanoscribe $\mathrm{GmbH}$ ) was used for producing master 3D microstructures by $2 \mathrm{PP}$. The structures were developed using propylene glycol monomethyl ether acetate (PGMEA, RER600, Arch Chemicals) and rinsed using isopropyl alcohol (IPA, Sigma-Aldrich). Polydimethylsiloxane (PDMS, Sylgard 184 elastomer, Dow Corning) and fluoroctatrichlorosilane (FOTS, SigmaAldrich) were used for microlithography procedure to finally emboss PLA films (Corbion Purac ${ }^{\circledR}$, Corbion), 
A

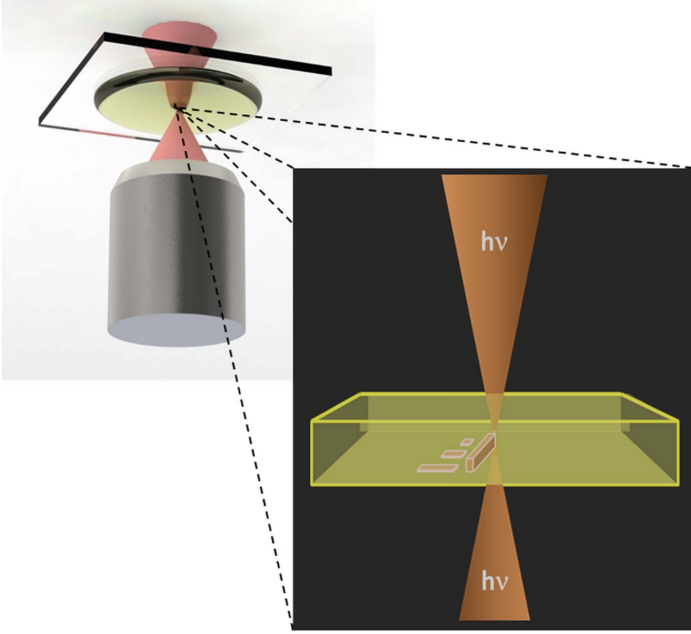

B

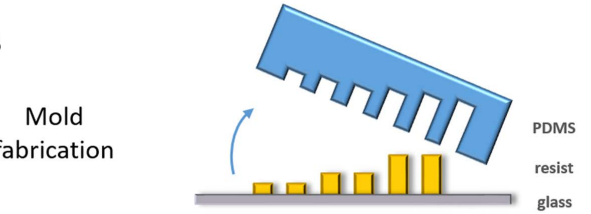

Biopolymer embossing

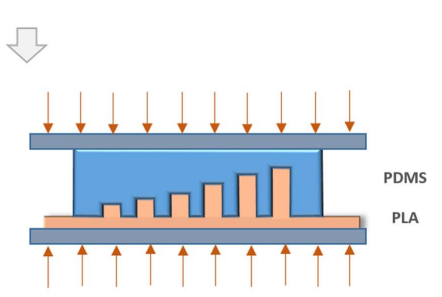

C
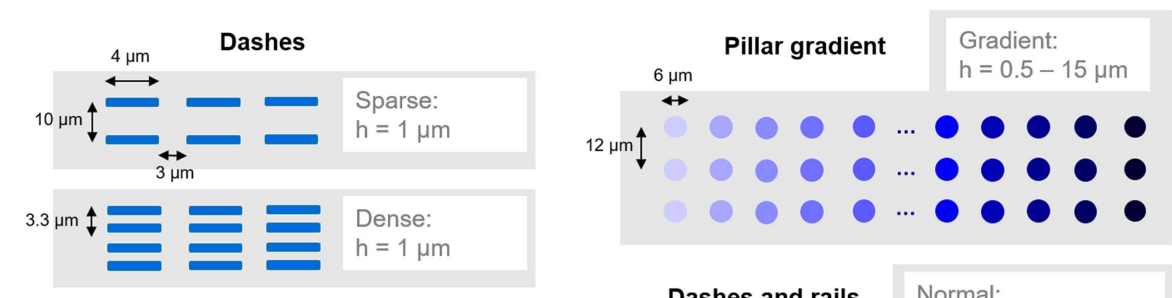

Sample pre-treatment

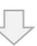
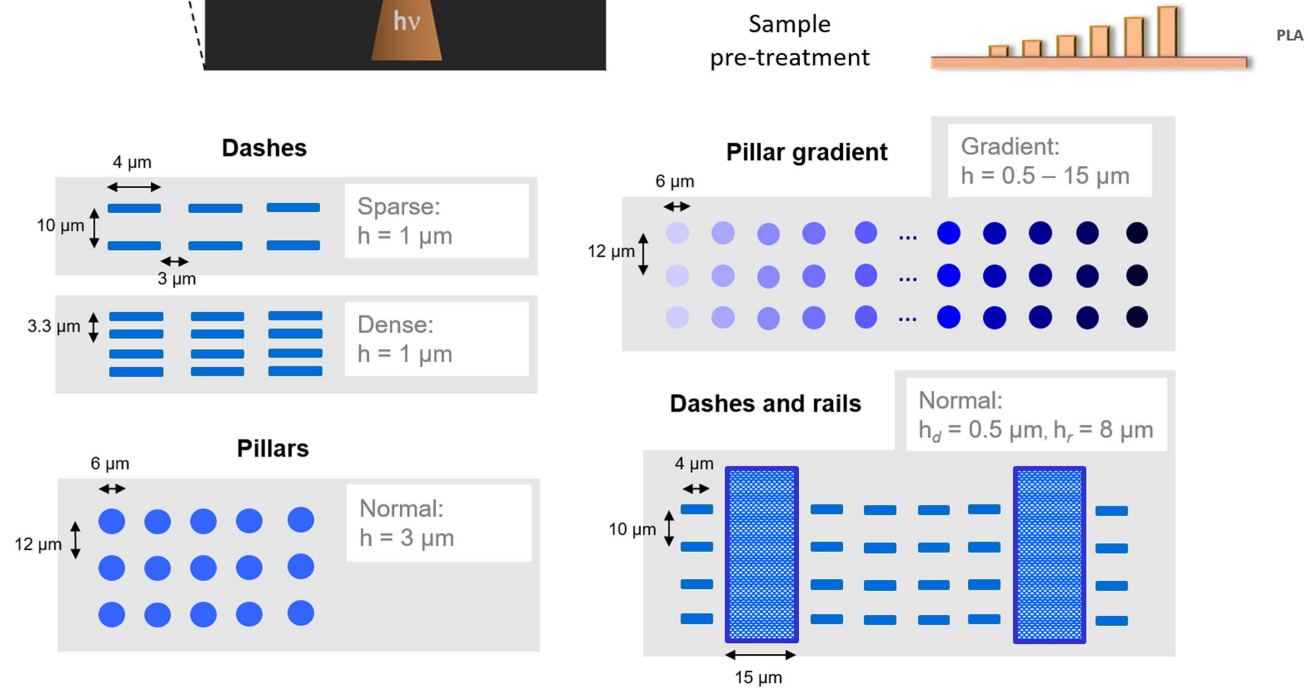

Figure 1. Schematic representation of the two-step prototyping process for micropatterning of 3D objects on PLA surfaces. Each group of micro-objects was fabricated by (A) $2 \mathrm{PP}$ followed by (B) replication into PLA using hot embossing via an intermediate PDMS mold. The final micropatterns in PLA had similar size and aspect ratio as the original patterns produced using $2 \mathrm{PP}$. (C) Concept design of different groups of micropatterns: dashes of equal dimensions and equal distance in a single direction, but different distance in the perpendicular direction (sparse and dense dashes), cylindrical pillars with either constant height or with the height varying in a gradient-wise manner (pillars and pillars gradient) and dashes perpendicularly crossed by rails with a height about a tenfold of that of the dashes (dashes/rails).

providing them with microstructures. Components for cell culture such as Minimum Essential Medium $\alpha$ ( $\alpha$-MEM), fetal bovine serum (FBS), penicillin-streptomycin (Pen/Strep), L-glutamine (L-glu) and trypsin in ethylenediaminetetraacetic acid (trypsin-EDTA) were from Gibco, Life Technologies. Bovine serum albumin (BSA) was from Sigma-Aldrich. For fluorescence microscopy, the following probes were used: fluorescein isothiocyanate (FITC) conjugated antibody for vinculin (F7053, Sigma-Aldrich), antivimentin (ab92547) primary antibody and anti-rabbit Alexa Fluor ${ }^{\circledR} 647$ as secondary antibody (from R\&D Systems), CF ${ }^{\mathrm{TM}} 594$ phalloidin (Biotium) for cytoskeleton, 4',6-Diamidino-2-phenylindole dihydrochloride for nuclei (DAPI, Sigma-Aldrich).

\subsection{Master design and production by $2 \mathrm{PP}$}

Drawings of the objects for 2PP printing were made using Solidworks (Dassault Systèmes) and the files were saved in STL format. The following pattern designs were used: (i) arrays of semi-continuous ridges (dashes), with two different densities (dense and sparse dashes); (ii) arrays of pillars with either a constant height or with a height varying in gradient-wise manner (pillars and pillars gradient); and (iii) array of semi-continuous lines/dashes perpendicularly crossed by larger, continuous ridges/rails (dashes/rails). Groups of patterns are exhibited in figure 1(C). Fabrication of the 3D microstructures was performed with a 3D laser lithography system (Nanoscribe GmbH, Photonic Professional). Conversion into machine language was done using the proprietary software belonging to the equipment manufacturer. The excitation source was a Ti-Sapphire femtosecond (fs) laser with a wavelength of $780 \mathrm{~nm}$, emitting $150 \mathrm{fs}$ pulses at $100 \mathrm{MHz}$ and $20 \mathrm{~mW}$ at sample surface. The laser beam was focused within the resin using a $100 \times$ or $63 \times$ microscope objective with a numerical aperture of 1.4 and 0.75 , respectively. A resin drop (IP-L, Nanoscribe) was placed on top of a 
$0.17 \mathrm{~mm}$ glass cover slide, and positioned in the sample holder (schematic in figure 1(A)). Whenever $100 \times$ objectives were needed, a drop of oil was placed between the cover glass and the lens. After exposure, development was done using PGMEA during 5-10 min, followed by rinsing with IPA and drying using gentle nitrogen blow.

\subsection{Replication of $2 \mathrm{PP}$-generated micropatterns into PLA by microlithography}

2PP master structures on glass surfaces were replicated into PLA by microlithography using an intermediate PDMS mold (schematic in figure 1(B)). First, a nonsticking coating was prepared on the master structures using simple chemical vapor deposition of FOTS within a sealed petri dish, which was pre-heated at $120^{\circ} \mathrm{C}$ for $15 \mathrm{~min}$, and incubated for at least $2 \mathrm{~h}$. PDMS was mixed with the curing agent in a 10:1 ratio, stirred for $5 \mathrm{~min}$ to homogenize and centrifuged at $4000 \mathrm{rpm}$ for $1 \mathrm{~min}$ to remove air bubbles. The mixture was cast onto the master structure, placed inside a desiccator connected to a vacuum pump for 15 min for further degassing and better PDMS fill of smallest spacing between features. Finally, the PDMS was cured in the oven for $3 \mathrm{~h}$ at $65^{\circ} \mathrm{C}$ and removed for final cleaning. PDMS molds were then used to hot emboss PLA films. Embossing was performed at $150{ }^{\circ} \mathrm{C}$ for $15 \mathrm{~min}$, using a hot-press (Fontijne Holland), followed by slow cooling down to room temperature before demolding. Micropatterned samples for cell culture were cut with a steel puncher to disks fitting in 24-well cell culture plates.

\subsection{Materials characterization}

The morphology of the microstructures in polymer obtained after 2PP and replication via hot embossing was assessed using scanning electron microscopy (SEM; Philips XL-30). Dimensions and periodicity of the structures were evaluated by scanning and subsequent quantification in a $3 \mathrm{D}$ microscope equipped with white light interferometry mapping (Bruker Contour GT-I).

\subsection{Cell culture}

Prior to cell culture, all samples were plasma treated for $45 \mathrm{~s}$ (PDC-002, Harrick Scientific), and placed into 24 -well plates in triplicate. For sterilization, samples were incubated twice in $70 \%$ ethanol for $5 \mathrm{~min}$, twice in sterile phosphate buffered saline (PBS) for $5 \mathrm{~min}$, and then immersed in cell culture medium ( $\alpha$-MEM supplemented with $10 \%$ FBS, $1 \%$ Pen/Strep and $1 \%$ $\mathrm{L}$-glu) for at least $1 \mathrm{~h}$ before cell seeding in fresh medium. Prior to seeding on the substrates, human osteosarcoma cells MG-63 were subcultured at $37^{\circ} \mathrm{C}$ in a humidified atmosphere with $5 \% \mathrm{CO}_{2}$. Medium was replaced every $2 \mathrm{~d}$. Upon reaching 80\%-90\% confluence, cells were trypsinized with $0.25 \%$ trypsinEDTA for $5 \mathrm{~min}$ at $37^{\circ} \mathrm{C}$ and then seeded onto the micropatterned substrates inside 24 -well plates at a density of 7500 cells $\mathrm{cm}^{-2}$, in a working volume of $1.5 \mathrm{ml}$ cell culture medium per well.

\subsection{Fluorescent staining and imaging}

Cell attachment and morphology $(n=3)$ were evaluated by a four-channel fluorescence imaging of nucleus, F-actin, vinculin and vimentin. Upon culture for 1 or $3 \mathrm{~d}$, the medium was removed, and the samples were washed with PBS and fixed with $4 \%$ paraformaldehyde for $20 \mathrm{~min}$ at room temperature. For fluorescent staining, samples were washed twice with PBS, permeabilized with $0.1 \%$ Triton X-100 in PBS for 5 min, and washed twice with $0.1 \%$ Tween-20 in PBS (PBST). They were first incubated in blocking buffer (2\% BSA in PBST) for $30 \mathrm{~min}$, and subsequently with anti-Vinculin-FITC (1:750 in blocking buffer) in combination with primary rabbit antibody for Vimentin (1:450 in blocking buffer) overnight. On the next day the samples were washed twice with PBST, incubated with F-actin probe $\mathrm{CF}^{\mathrm{TM}} 594$ phalloidin (1:40 in PBST) combined with secondary antibody Alexa Fluor ${ }^{\circledR} 647$ anti-rabbit (1:400 in PBST) for $1 \mathrm{~h}$, washed twice with PBS and finally incubated with DAPI (1:100 in PBS) for 15 min to stain the nuclei. The samples were then washed again and left in PBS. Incubation with fluorescent dyes was performed at room temperature in the dark. Cells were observed with a fluorescence microscope equipped with a mercury lamp, BD Pathway ${ }^{\mathrm{TM}} 435$ (BD Biosciences, USA), at a magnification of $20 \times$ with multiple frame acquisitions.

\subsection{Image processing and quantification}

Cell morphology was analyzed qualitatively and quantitatively. Prior to the analyzes, multi-frame multicolor images were processed through FIJI (Image J) for stitching, color stacking, rotation and related assemblies, respecting initial scales and aspect ratios. Quantitative analysis in terms of cytoskeleton organization upon attachment and proliferation was performed using CellProfiler image analysis software [40]. The parameters chosen to describe the cell morphology were the area, eccentricity, major and minor axis, and orientation. Cell area was given by the number of pixels occupied (arbitrary units, a.u.), eccentricity was used as a descriptor for cell aspect ratio (ellipse shape, with 0 being a perfect circle and 1 being a line), and major and minor axis in pixels for aspect ratio measurements. Cell orientation was determined by the angle between the $x$-axis and cell's major axis (in degrees, ranging from $0^{\circ}$ to $90^{\circ}$ ). The parameters chosen to describe nuclei shape were solidity and orientation. Solidity, also known as convexity, gives the proportion of the pixels in the convex hull that are also in the object (nucleus), and was computed as Area/ConvexArea in CellProfiler. 


\section{Results}

\subsection{Material characterization}

SEM images of the topographical micropatterns in PLA obtained using the two-step process consisting of 2PP and hot embossing via an intermediate PDMS mold are shown in figure 2. Furthermore, the figure shows the maps and quantification of the size and periodicity of the micro-objects obtained using white light interferometry along the longitudinal and transversal axes of the samples. A general observation was that the replications process induced minor deviations to the predicted CAD design of the features.

Two types of semi-continuous linear patterns were designed with varying distance between the lines, making a first group of structures: dense dashes (figure 2(A)) and sparse dashes (figure 2(B)). Both patterns demonstrated that the microstructures, initially created using $2 \mathrm{PP}$, were successfully transferred into PLA using embossing. The SEM/profilometry data showed semi-continuous lines in aligned segments, having a length of $4 \mu \mathrm{m}$ and the distance between individual segments of $3 \mu \mathrm{m}$. The distances between the semi-continuous linear segments were $10 \mu \mathrm{m}$ and $3.3 \mu \mathrm{m}$ for sparse and dense dashes, respectively, closely resembling the initial CAD design.

To further explore the effect of sub-cellular dimensionality of the topographical features, a square array of pillars was produced. The final pillar arrays in PLA either had a constant height of $3 \mu \mathrm{m}$ (figure $2(\mathrm{C})$ ), or presented a gradient of heights from 0 to $15 \mu \mathrm{m}$, in steps of $0.5 \mu \mathrm{m}$ (figure 2(D)). The diameter of the pillars with constant height was about $6 \mu \mathrm{m}$ and the spacing between individual pillars $4 \mu \mathrm{m}$, whereas in pillars gradient the diameter was about $6 \mu \mathrm{m}$ and the spacing $6 \mu \mathrm{m}$. Both structures presented some deformation as compared to 2PP-produced structures, either on the vertical 'walls' of the pillars or on pillar tops, as is seen in the height profile. The wavy profile on the top of the pillars was a result of $2 \mathrm{PP}$ microstructuring, whereby voxels are not close enough to provide a homogeneous, flat surface. The deformation in the pillar wall profile may be introduced by the PDMS mold deformation as a result of the pressure applied during embossing. Furthermore, consequences of a higher embossing stress were also visible on the higher pillars of the gradient samples. The higher pillars had a somewhat smaller diameter than the lower pillars in the same sample (figure 2(D), transversal profile), suggesting that the on the upper side, the higher pillars undergo a more pronounced deformation in the mold than the lower ones. Despite these small deformations, the micropatterns with different aspect ratios were successfully created to instruct cell attachment and direct alignment.

The final pattern consisted of dashed lines with a width of approximately $0.5 \mu \mathrm{m}$, and distance between individual dashes and between dashed lines of $10 \mu \mathrm{m}$, that were crossed by larger ridges, or 'rails', having a height of $8 \mu \mathrm{m}$ and a width of $10 \mu \mathrm{m}$ (figure 2(E)).

\subsection{Cell morphology and orientation}

The osteoblast-like MG-63 cells were cultured on the PLA micropatterns for $24 \mathrm{~h}$ to assess their attachment and morphology. On flat, unpatterned surfaces, the cells exhibited a random distribution and a large range of area sizes. The minor cell axis had an average length of about 100 pixels and a narrow size distribution, whereas the major axis, with an average length of 175 pixels, showed larger size variations. Cell eccentricity was relatively high (above 0.75 ), showing that the cells had the tendency to elongate on unpatterned surfaces (supplementary figure 1 is available online at stacks.iop.org/BF/9/035004/mmedia). No preferential orientation was observed on flat samples.

As is shown in figure 3(A), it was observed that, in general, the dashes had a strong effect on cell alignment. Cells aligned along the dashed lines, regardless of the dash density. Although no changes in cell area were observed between cells cultured on dense and on sparse dashes, the cell shape was somewhat affected, with cells grown on sparse dashes being slightly more elongated, while keeping the same width (minor axis). This observation was reflected in high cell eccentricity for both patterns, although the values on dense dashes were slightly lower than on sparse dashes.

Figure 4 shows the shape descriptors of the cells cultured on the arrays of pillars, either with a constant height or with varying heights. The quantification of cell morphology parameters indicated that a height threshold exists for the ability of cells to grow over the topographical features. Indeed, on the pillar gradient samples it was observed that when the height of the pillars was $3 \mu \mathrm{m}$ or higher, the cells could not spread over the pillars, but instead were confined between them. The pillars with a height up to $2.5 \mu \mathrm{m}$ exhibited cell spreading over the features. These observations from the pillars gradient were confirmed on the pillars with constant height of $3 \mu \mathrm{m}$ where the cells were found between the pillars, rarely covering them.

Cell area measurements showed a decreasing trend towards higher pillars, which may be a result of the confinement of the cells between the pillars, but also of the adhesion along the pillar walls. The cells in contact with pillars with a height above $2.5 \mu \mathrm{m}$ showed high eccentricity, imposed by the pattern features, and consequently, they were highly aligned either in $0^{\circ}$ or $90^{\circ}$ direction. This was the case both for pillars and pillars gradient samples.

To further investigate how the size of the structural features affects the attachment and growth of the cells, the culture was performed on dashes/rails samples. As is shown in figure 5, the dashes, which have shown a significant effect on cell alignment (figure 3(B)), did not play a significant role in cell alignment, when 

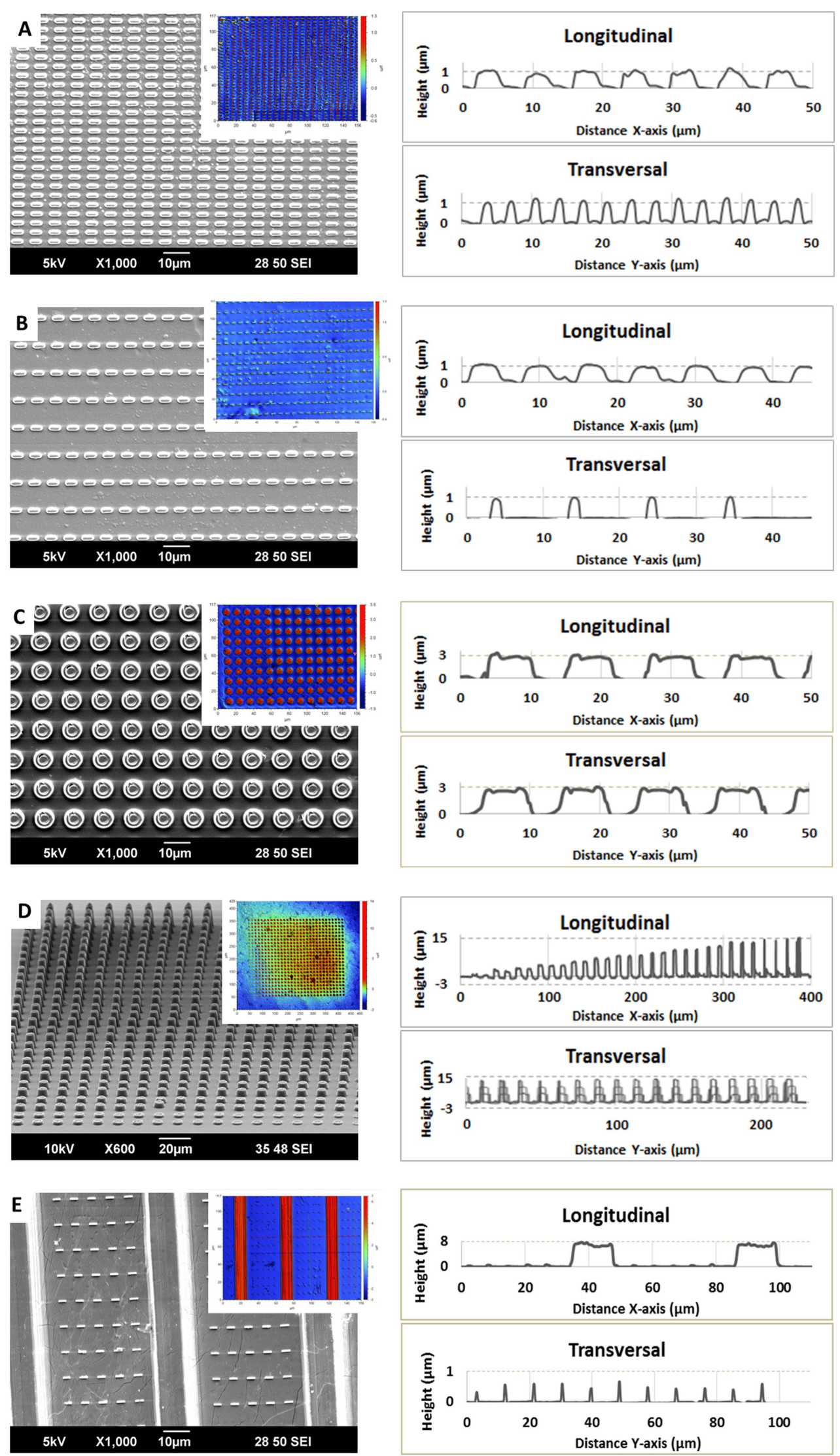

Figure 2. Scanning electron microscopy and white light interferometry height profile mapping of the microstructures on PLA surfaces: dense dashes (A), sparse dashes (B), pillars (C), pillars gradient (D), dashes/rails (E), and representative profile lines of height measurements in two directions. 

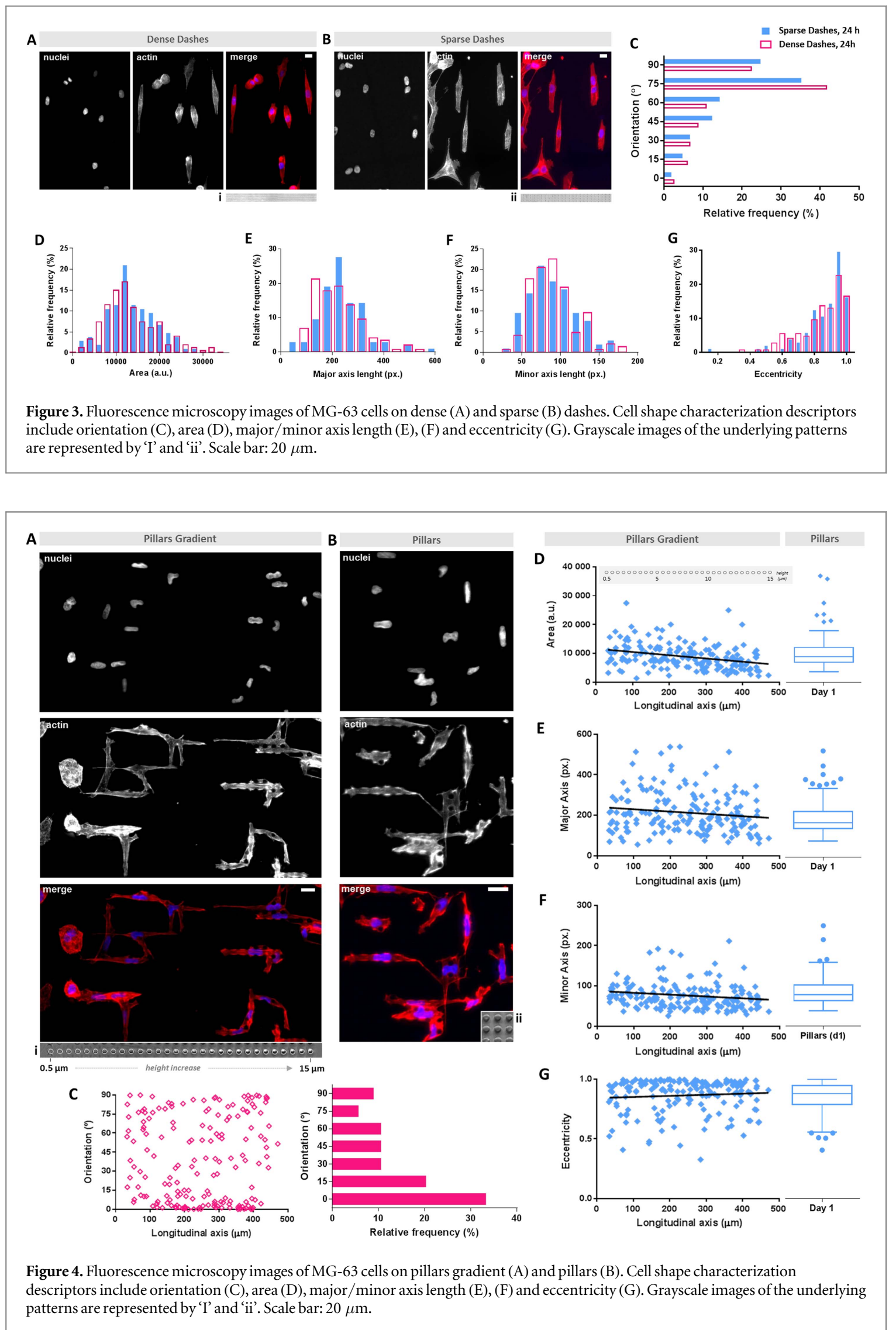

combined with much larger rails (figures 5(A), (B) and (G)). Indeed, the results showed that both in presence and in absence of dashes, cells always aligned in the direction of the rails. When the cell shape is considered, the values for cell area were similar for both rails and dashes/rails (figure 5(C)), but an increase in the extent 

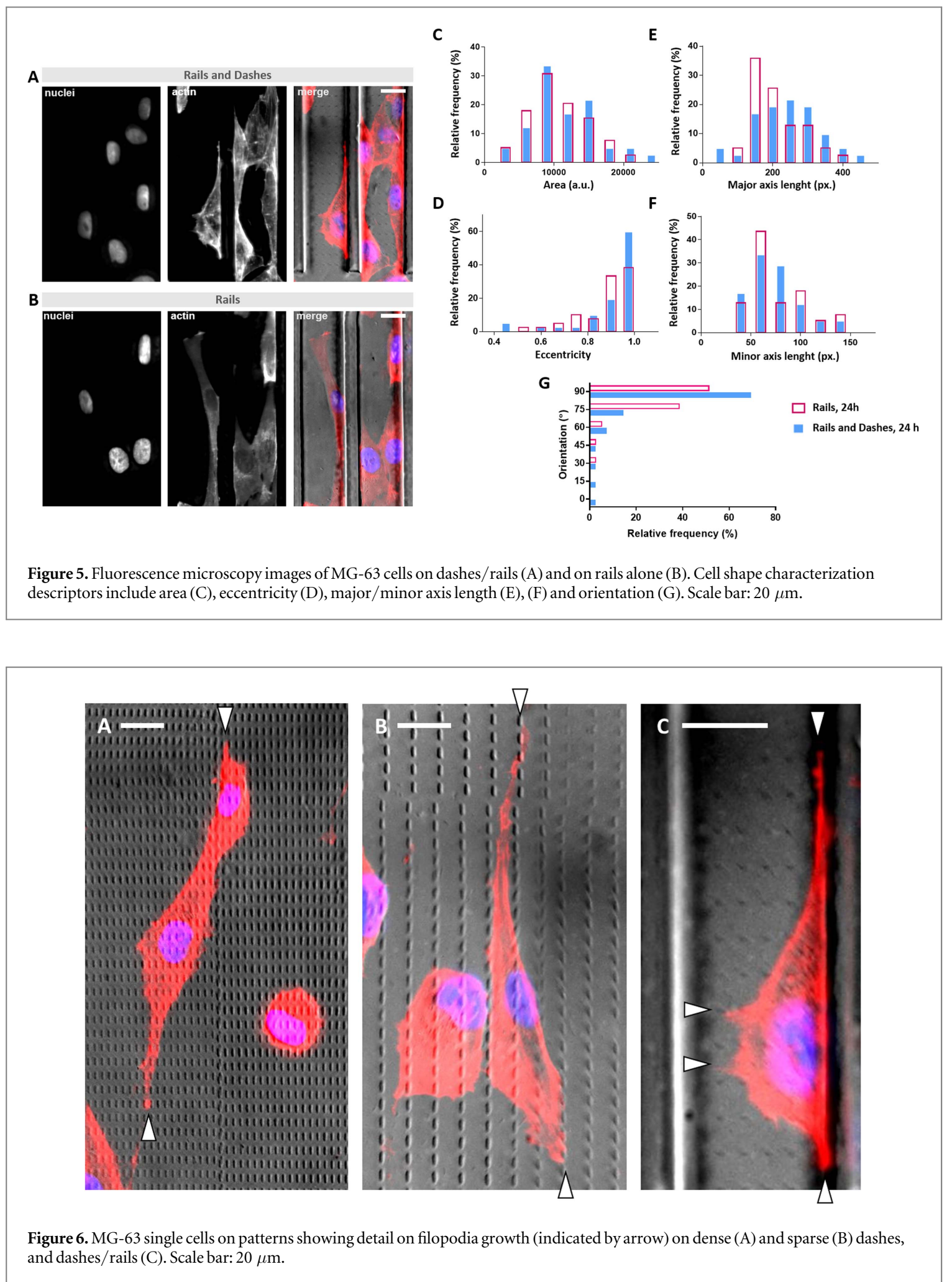

of elongation (major axis) and a small increase in width (minor axis) were observed on dashes/rails as compared to rails alone (figures $5(\mathrm{E})$ and $(\mathrm{F})$ ), also reflected in less very eccentric cells at the rails (figure 5(D)).

While the effect of the larger rails on cell orientation was much stronger than the effect of the dashes, higher magnification images showed that dashes did have an effect of cell spreading, with filopodia protrusions attaching to them (figure 6).
Taken together, the cell shape parameters on the different groups of micropatterns showed that the dashes were able to orientate the cells, both on sparse and on dense patterns, and that the density had a mild effect on cell shape. However, when the dashes were combined with larger rails, the latter had a stronger effect on cell orientation, while the effect of the dashes was predominantly seen in extending filopodia. Finally, the pillars arrays showed that the height of the 

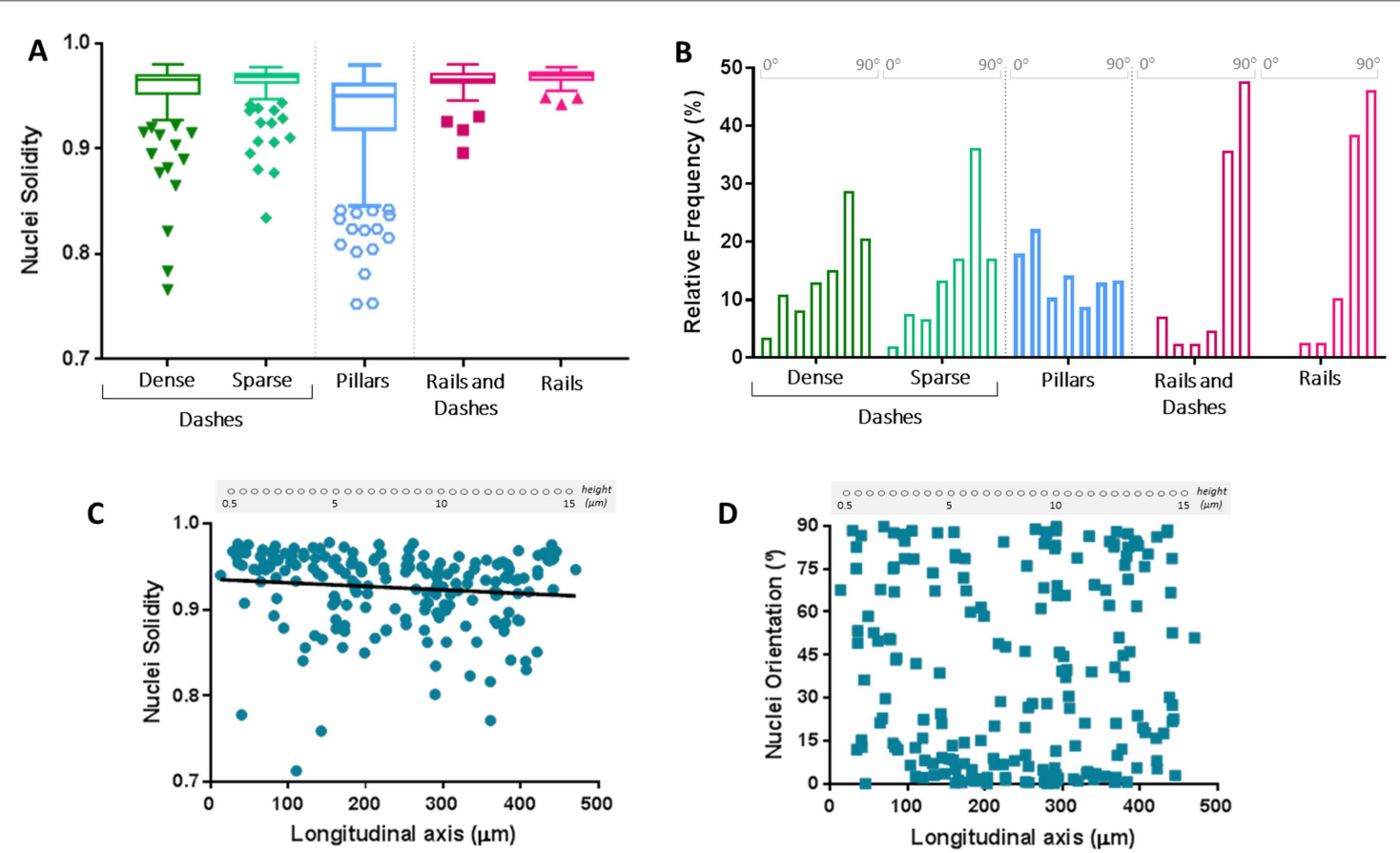

Figure 7. Morphological characterization of nuclei shape of MG-63 cells cultured on the micropatterned PLA surfaces for 24 h. Nuclei solidity (A), (C) and orientation (B), (D) are shown for the cells cultured on dashes, pillars and dashes/rails and rails without dashes (A), (B) and on pillars gradient (C), (D).

microsized features is important in determining whether the cells will spread over the features or be confined between them.

\subsection{Nuclei deformation}

In addition to the analysis of the effects of structural micropatterns on cell shape, changes in the cell nuclei shape were also investigated. Figure 7 shows details of nuclei deformation in the form of solidity and nuclei orientation. Solidity provides a differentiator for objects with protrusions or irregular shape versus generally round objects, with lower solidity corresponding to a more irregular-shaped nuclei. Regarding the shape, the results indicated that the nuclei of the cells cultured on the pillars showed the lowest mean value for solidity, along with the highest data variability (figure 7(A)). In contrast, the cells cultured on dashes or dashes/rails exhibited a higher mean solidity as compared to the pillars. Also the distribution of orientation data for the nuclei on pillars was more homogeneous than in other samples. It was furthermore observed that the cells cultured on dashes showed lower nuclei solidity values as compared to the cells cultured on dashes/rails samples. Regarding the pillars gradient sample, a decreasing trend in nuclei solidity was observed with the increasing height of the pillars in the gradient (figure 7(C)).

No preferential nuclei orientation was observed for cells cultured on the pillars (figure $7(B)$ ), whereas on the pillars gradient (figure $7(\mathrm{D})$ ), the frequency of cells showing the values of $0^{\circ}$, i.e. oriented in the direction of the gradient, significantly increased above the $2.5 \mu \mathrm{m}$ threshold, which was in accordance with the observation on cell shape. On the dashes/rails samples (figure 7(B)), a strong orientation of the cell nuclei was observed in the direction of the rails, which was also observed for the cells as a whole.

\subsection{Focal adhesions}

To further investigate the role of topographical features on the formation of focal adhesions, immunohistochemical staining was performed for vinculin on cells grown on smaller topographical units, i.e. dashes and pillars. The analysis of early events of vinculin cluster formation in this mature type of adhesion complexes is valuable to understand the effect of micropatterns on cell attachment forces.

After $24 \mathrm{~h}$ of culture, abundant presence of soluble vinculin was observed on both dense and sparse dashed surfaces (figures $8(\mathrm{~A})$ and (B), respectively), suggesting that this time point was too early to observe vinculin clustering, which takes place during focal adhesion maturation [41]. In contrast to dashes, cell elongation between the pillars was followed by an increase in intensity of stained vinculin, mainly due to the increased compaction on cells (thus, lower spreading area), as compared to flat or dashed surfaces. Indeed, the elongation of cells on pillars samples led to the formation of actin stress fibers and often to filopodia, in which a high accumulation of vinculin was observed (arrows in figure $8(\mathrm{C})$ ).

\subsection{Effect of micropattern feature height on stress fibers and vimentin displacement}

The pillars gradient samples were further used to investigate the effect of micropattern feature height on cytoskeleton organization, with the rationale that the topographical feature height is important for defining 

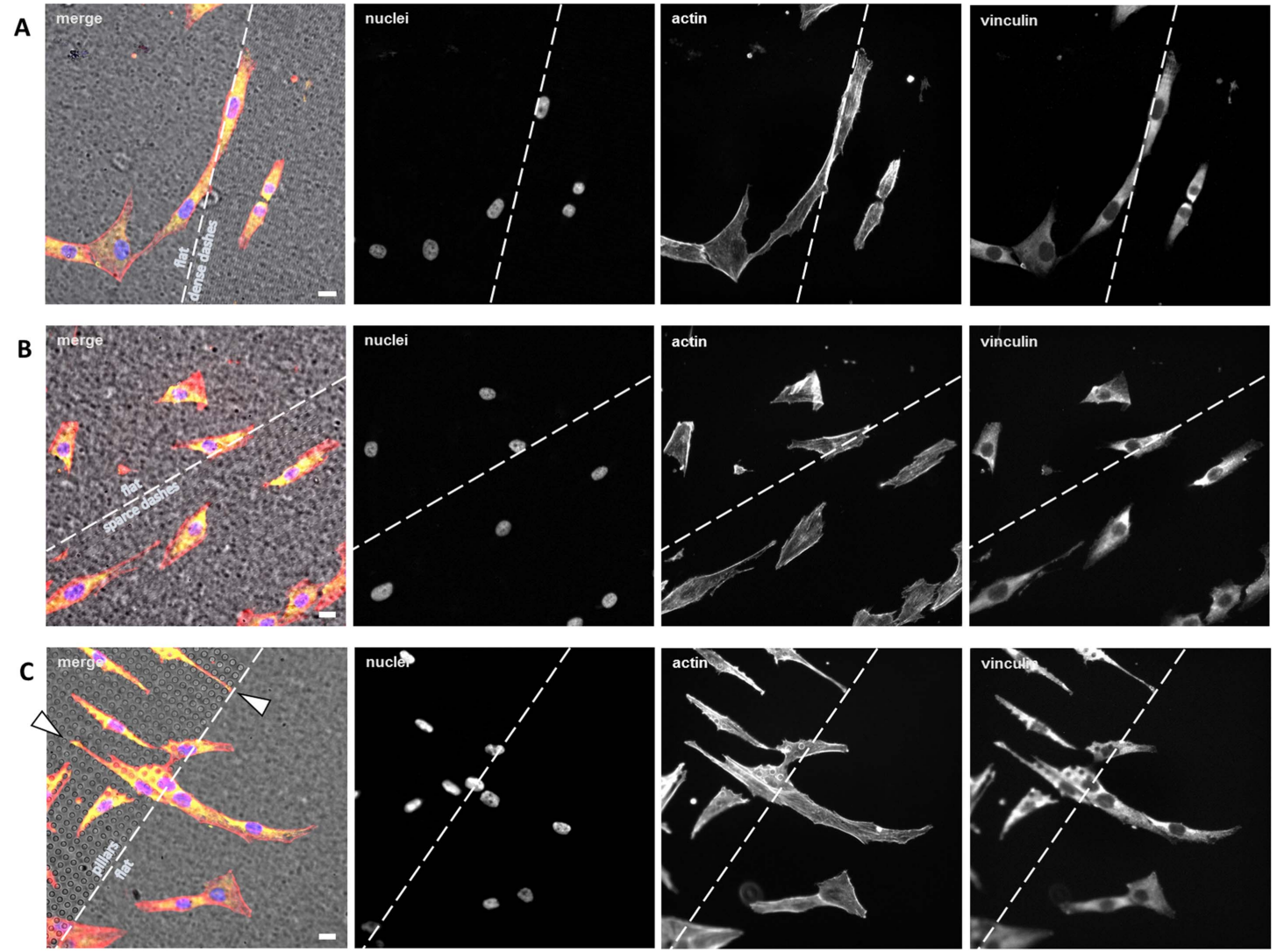

Figure 8. Fluorescence microscopy images of MG-63 cells on patterns/flat surface and specific immunohistochemical staining for vinculin after $24 \mathrm{~h}$ of seeding. Color merge, nuclei, actin and vinculin independent channels are presented for dense (A) and sparse (B) dashes, and pillars (C). Main vinculin aggregates are indicated by arrows. Scale bar: $20 \mu \mathrm{m}$.

the type if interaction between the different sub-cellular components. While focal adhesion complexes are expected to sense nanoscale topographical features [19], the microsized pillars as investigated here are in the same scale as major components of cytoskeleton, including the actin filaments, intermediate filaments (IF) and microtubules. Figure 9 confirms the earlier discussed observation that, with an increasing height of the pillars, the cells became confined between the features, unlike in the case of lower pillars, where they retained the ability to spread over the features, with the height threshold being at $2.5 \mu \mathrm{m}$. Furthermore, the cells that were confined between the higher pillars showed a more anisotropic spreading, getting elongated in one direction, and undergoing polarization, which was assisted by the formation of a high-density system of parallel stress fibers with a leading edge. Furthermore, in these polarized cells, an inhomogeneous distribution of vimentin was observed, probably counter-balancing the scaffolding tension exercised by the actin fibers through cell's major axis. Vimentin, absent on top edges of the cells, showed a high concentration only at the siding cell edges, and more specifically, in the areas of the cell edges connecting individual pillars.

In contrast to these elongated cells, the cells in contact with lower pillars showed a lower density of actin and a more even distribution of vimentin. This was reflected by more spread cell shapes, having protrusions 'exploring' the surface in multiple directions.

\subsection{Effect of micropattern feature height on cytoskeleton condensation}

Following the initial attachment of individual cells on the material surface, multiple cell layers are formed with prolonged culture time. To investigate the effect of micropattern features on the interaction between cell layers, the condensation of cytoskeleton was analyzed by thresholding the images of actin fluorescence of confluent cells cultured for $3 \mathrm{~d}$. As is shown in figure 10, in cells cultured on dashes, an even distribution of sharply defined actin fibers was observed, independent of the feature density. In pillars gradient samples, the level of condensation of actin fibers was shown to be dependent on the height of the pillars. On lower pillars, sharply defined, thin actin fibers were observed, getting more condensed on pillars with an intermediate-height range, and finally predominantly condensed fibers on the highest pillars. On the highest pillars, clear stacking of cells was observed in the vertical direction, which may be in a part responsible for this high skeleton density. On dashes/rails samples, smaller dashes did not seem to affect the concentration of cells, which were predominantly concentrated between the rails, frequently covering them. 


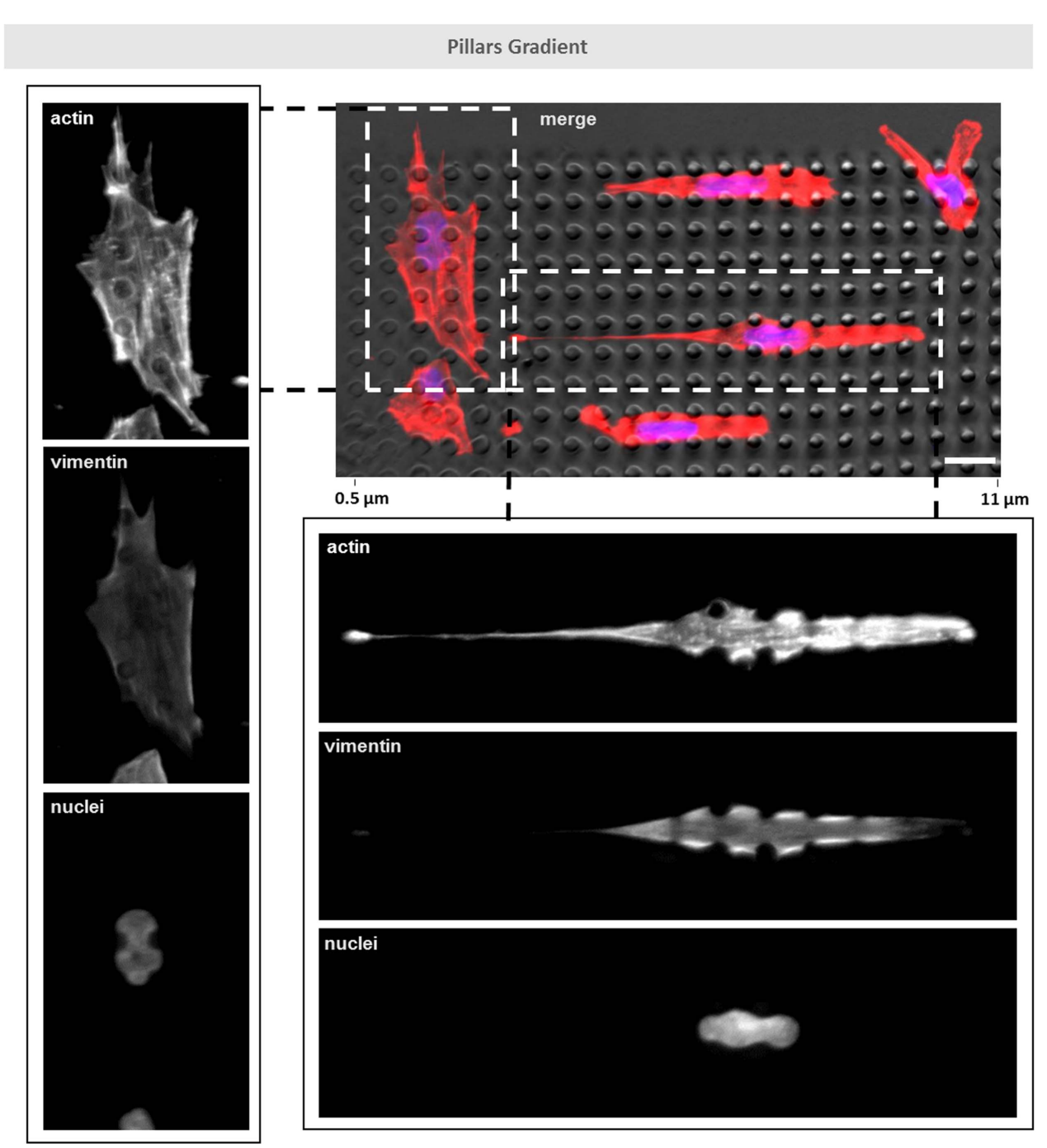

Figure 9. Fluorescence microscopy images of MG-63 cells on pillars gradient array $24 \mathrm{~h}$ after seeding. Higher magnification images show independent actin, vimentin and nuclei channels, respectively. Scale bar: $20 \mu \mathrm{m}$.

\section{Discussion}

The mechanical interactions between cells and the biomaterial surface play a major role in the development and regeneration of tissues. The influence of mechanical cues guiding tissue formation largely depends on the chemistry and geometry (dimension, frequency) of the material surface, leading to a set of mechanotransduction events, which eventually result in definitive cell commitment [3, 38, 42]. Design of these biomaterial properties at different length scales is therefore a highly powerful tool to direct mechanotransduction signaling or indirectly affect cytoskeleton contractility, which will likely contribute to defining the activation of specific pathways [3, 42-47]. Indeed, several examples have demonstrated the importance of topography [20, 48], stiffness [47, 49], mechanical stress (tensile/compressive) [50-52], shear flow $[52,53]$, or combinations thereof [54-58] in controlling cell fate.

While surface topography is becoming increasingly recognized as a valuable tool to instruct cell behavior, including differentiation, the exact mechanisms by which the micro and nanostructural surface properties of a material affect molecular cell biology, inducing a specific cell phenotype, are still incompletely understood. Nevertheless, many researchers have developed methods to help disclosing how surface patterning interferes with these mechanisms. For example, in a range of elegant papers, Dalby and coworkers have reported on the effects of nanotopography in determining cell fate [19, 59-61]. Indeed, surface nanopatterns have been described to directly influence maintenance of pluripotency [60], and induction of differentiation [62]. Studies have demonstrated direct effects of nanotopographical factors on differentiation of human mesenchymal stromal cells along the osteogenic lineage [61, 63], as well as on dental implants osteointegration [42].

In addition to the studies focusing on the effect of topographical cues at the nanometer scale, to elucidate the mechanisms underlying the formation of focal adhesion complexes [64-67], many researchers have focused on mechanotransduction events at the 
A

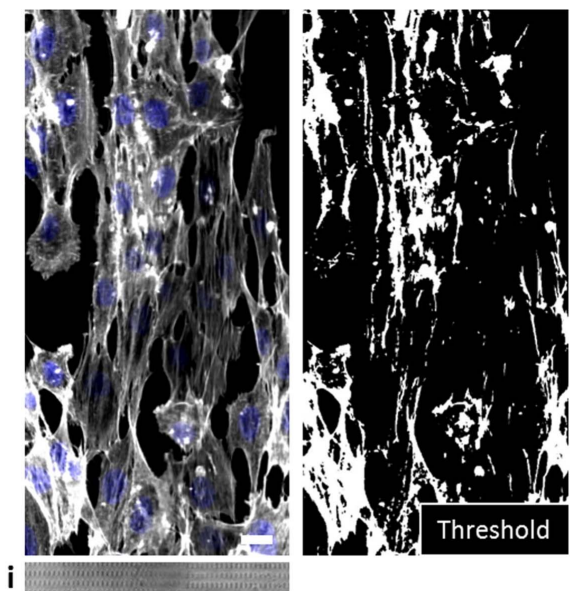

B

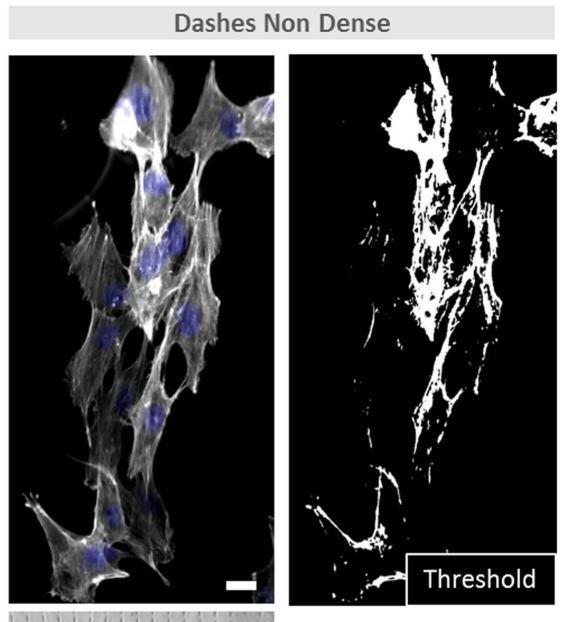

ii

C

Pillars Gradient

iii
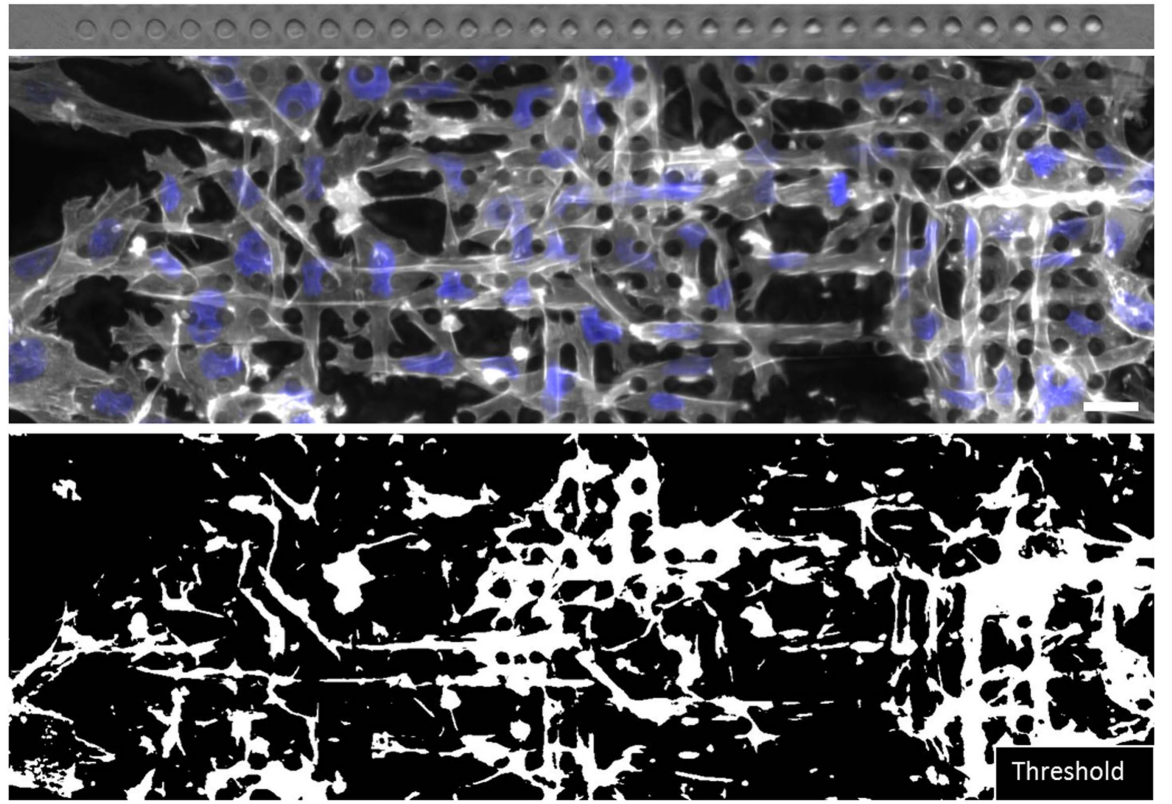

D

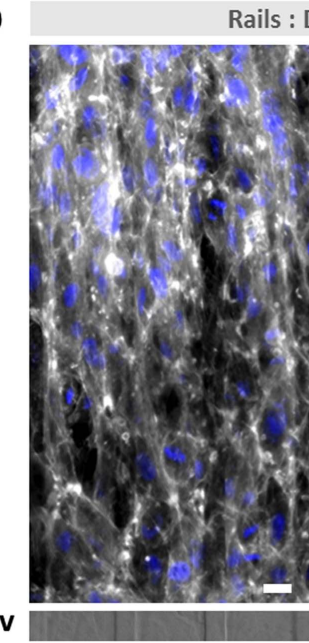

Rails : Dashes +
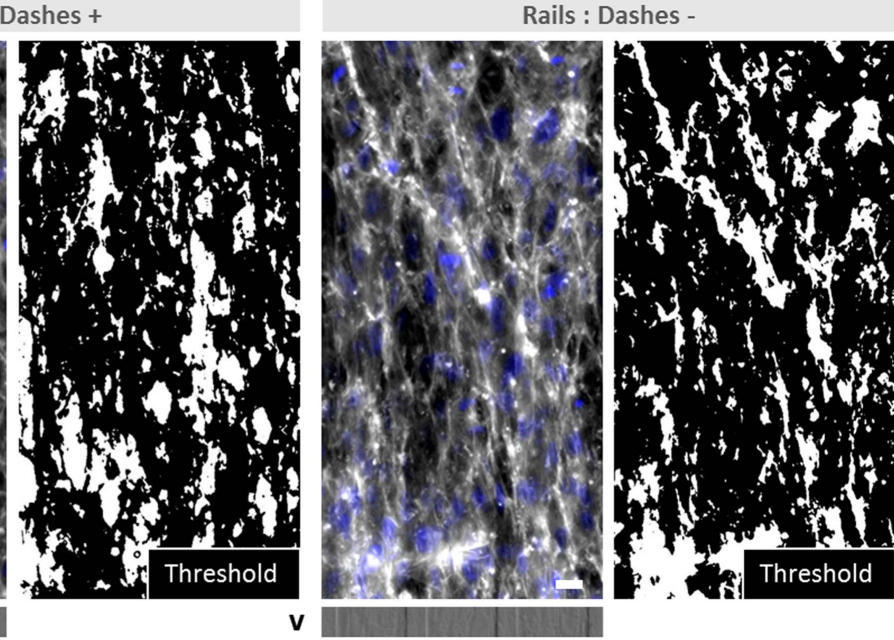

Figure 10. Fluorescence microscopy images of actin (grayscale) and nuclei (blue) and the thresholded grayscale image of cytoskeleton from confluent cell layers of MG-63 cells cultured for $3 \mathrm{~d}$ on micropatterned surfaces: (A and B) dashes, (C) pillars gradient and (D) dashes/rails (as represented in bright field side images, $\mathrm{i}-\mathrm{v}$ ). Scale bar: $20 \mu \mathrm{m}$. 
micrometer scale [68-70]. Furthermore, a number of studies focused on the effects of microscale topographies on cell differentiation $[42,71,72]$ and even the formation of micrometer-sized tissue [20]. Such studies demand the techniques that provide high-resolution. Electron beam lithography coupled with embossing [46] and photolithography combined with ion etching and molding [73] are among the most popular techniques for providing surfaces with topographies at the smallest scales. Despite specific advantages, both techniques are generally used to build topographical features with a single height, given that commonly a single layer of resist is patterned at a time. In our study, $2 \mathrm{PP}$ was used as a valuable direct additive manufacturing technique allowing for close control over the surface topography features in $3 \mathrm{D}$ with high-resolution. Indeed, $2 \mathrm{PP}$ is a direct laser writing technique, used to structure materials commonly offering a resolution of few hundred nanometers [27, 28], and building of finely structured multiple scale features with a volume of up to few hundred micrometers in a single writing step. By employing an intermediate step of mold production and soft embossing, the micropatterns were reliably transferred into PLA, a widely used polymer in biomedical applications, overcoming the issues related to $2 \mathrm{PP}$, such as the need for photopolymerizable polymers and low production throughput. The behavior of MG-63 osteosarcoma cells was studied on these surfaces, as this is a widely used cell line, in particular in orthopedic and maxillo-facial research.

The first micropattern, consisting of an array of semi-continuous lines/dashes, demonstrated the influence of the dashes on cell alignment, and, depending on the density of the features, also on cell eccentricity. Furthermore, these micropatterns strongly guided the development of filopodia, fine projections of cell membrane, despite their semi-continuous nature. Filopodia act as primary microscale sensors of the biomaterial surface, where new focal adhesions complexes at nanoscale are formed under strong coordination of integrin interactions $[19,74]$. The relatively small $\left(4 \times 1 \mu \mathrm{m}^{2}\right)$ and low height $(1 \mu \mathrm{m})$ dashes were shown to provide support for contact guidance and create adhesion points defining cell alignment. However, they were not dominant enough to completely prevent the cell spreading in the direction perpendicular to the dashes direction, regardless of the pattern density, or to support the maturation of focal adhesions by vinculin clustering (at $24 \mathrm{~h}$ ). When dashes with a height of $0.5 \mu \mathrm{m}$ were combined with crossing continuous lines (rails), with a width and height about 15 times larger that of the dashes, the contact guidance effect that was initially observed for the dashes with a comparable height, was now disrupted by these larger features, not allowing the cells to further elongate in the direction of the dashes. Indeed, the cells were now fully aligned and elongated in the direction of the rails, overruling the contribution of the dashes to the contact guidance defining the major axis of the cell. Nevertheless, a minor effect on cell shape, i.e. an increase in cell eccentricity was observed in the presence of dashes, as compared to rails without the dashes, plausibly caused by the lateral filopodia development following the direction of the dashes (figure 6(C)). The threshold dimension for topographical features to influence filopodia and drive contact guidance has been suggested to be $35 \mathrm{~nm}$ in height [36], which is significantly below the height of the dashes in the patterns studied here.

The pillars micropattern, and more specifically, the gradient pattern, with pillars varying in height between 0.5 and $15 \mu \mathrm{m}$, provided an interesting platform to, in a single sample, study the sole effect of microfeature height on the cell behavior, while keeping the other parameters constant. The results showed that a critical height of the microfeatures of $2.5 \mu \mathrm{m}$ was required to orientate the cells and render them elongated, with a high form factor. While on the pillars with a height below $2.5 \mu \mathrm{m}$ the cells could easily spread radially, covering the features, on the higher pillars, they were confined between individual features, acquiring a more polarized shape.

It should be noted that MG-63 cells used in this study presented a highly irregular shape on flat surfaces, which was either three-edged, diamond shape, fusiform or combinations thereof, with the major axis length varying between ca 75 and $150 \mu \mathrm{m}$. Therefore, the topographical features tested here, having dimensions of up to $15 \mu \mathrm{m}$, are expected to play a role at a sub-cellular level, by limiting the spatial organization of the nuclei and cytoskeleton components. Furthermore, it is important to emphasize that, in contrast to studies using microforce sensor arrays [73], where micropatterned elastomers are used, and where topographical features may deform during interactions with cells, the PLA substrates as used here are rigid. Therefore, the observed effects on the cells are solely a result of the size and shape of the features.

It was observed that above a pillar height of $2.5 \mu \mathrm{m}$, the cells showed a high density of longitudinal stress fibers and a leading edge, which are both critical for cell polarization. In fibroblasts, this kind of events commonly surge as a morphogenetic response to increase in substrate stiffness [75, 76]. An increased vinculin density was observed at the peripheral edges of actin fibers on the major filopodia/leading edge, suggesting that the focal adhesions are involved in sensing the substrate stiffness [77-79]. This observation, supported by a clear cell response to the height and spacing on the pillars in terms of cytoskeleton aspect ratio and nuclear confinement, suggests that the micropatterned surfaces mimic the conditions of variable matrix-stiffness. In other words, we hypothesize that the same PLA (polymer with a high elasticity modulus) may mimic different local stiffness as a result of cell volume confinement caused by the microsized topography features. Prager-Khoutorsky et al [75] elegantly described a tracking system for 
assessing focal adhesion morphology and cell shape polarization in response to substrate stiffness, emphasizing that adhesions align prior to cells elongation. In our work, the same effect may have been triggered by dashes driving filopodia or by pillars defining a spreading axis. In fact, for stiffness sensing, a larger area than provided by the focal adhesions is required, and therefore, this process is more likely mediated by cytoskeleton. Moreover, it was previously suggested that actin cytoskeleton acts as a large-scale sensor that is responsive in milliseconds, as a results of the biomolecular machinery established between myosin II molecular motors and actin filaments [77]. Choquet et al [80] proposed that physical resistance to displacement of the substrate itself provides an additional cue used by cells to orientate during migration, in a process strongly regulated by integrin-cytoskeleton linkages. Cells cultured on pillars higher than $2.5 \mu \mathrm{m}$ showed a higher density of parallel stress fibers, and at a later stage, a more pronounced cytoskeleton condensation, a response also previously described for an increase in substrate-sensed stiffness due to topographical features [75, 77].

Regarding the effect of the micropatterns on cell nuclei, it was observed that nuclei with lower solidity, having a rod-like shape, were predominantly observed on the pillars and pillar gradient, even when the corresponding cells did not present a high eccentricity. Surprisingly, even on lower pillars, with a height below $2.5 \mu \mathrm{m}$, low-solidity nuclei were observed, deformed from their natural ellipsoid shape and presenting an irregular shape with lateral indentations. This effect may be a result of the tension pulling downwards against the lower pillars by the spreading cytoplasm, not allowing the nucleus volume to stay on top of the pillars. When cells were in contact with higher pillars, it is suggested that as a result of the vertical distance, membrane protrusions were prevented from reaching the top of the features. Consequently, the cells, and in particular the cell nuclei, with a more limited membrane plasticity, were deformed by the tension from the pillar walls. Tsimbouri et al [46] reported a similar phenomenon of nuclei compression as a result of large adhesion complexes. Higher tension forces sensed by nuclei on pillar micropatterns, unlike on the other surfaces, may affect lamina organization (part of the nucleoskeleton) [81, 82], ultimately leading to a repositioning of chromosomes [83] and affecting gene expression. Indeed, the signaling YAP/TAZ cascade has been identified as nuclear relay of mechanical cues exerted by ECM rigidity and cell shape [84]. Nevertheless, high cell eccentricity, observed both on pillars/pillars gradient and dashes/rails/rails also had an effect on cell nuclei shape, contributing to low solidity or highly pronounced orientation, respectively. Such pronounced alignment may result from a significant transduction of forces from focal adhesions of elongated cells to the nuclei through the individual components of the cytoskeleton, as proposed by Ingber et al $[74,85]$ in cellular tensegrity theory.

The cytoskeleton acts as the scaffold for cell's structure and is responsible for governing its mechanical properties. It mediates physical attachment and takes a key role in the regulation of several signaling pathways [86-90]. Cytoskeleton is composed by actin filaments, microtubules and IF. A major protein present in IF is vimentin, which contributes for the mesh anchoring the nucleus and radiates towards cell boundaries [91-93]. As observed on pillars gradient (figure $8(\mathrm{C})$ ), cell polarization resulted from confinement and extension through filopodia. In such events, vimentin is typically present in the rear and perinuclear region of migrating cells, but is almost absent in the protrusive regions [90, 92]. Unlike actin microfilaments and microtubule system, IF provide compliance under slight deformation, but provides stability and stiffness to the cell under great stress and deformation [88, 93-96]. Interestingly, whereas geometrical restrictions for cell spreading enabled the formation of long actin stress fibers, in case of vimentin, they contributed by providing support to the nuclei by intercalating the pillars in the region surrounding them. Again, it is the elastic nature of IFs such as vimentin that, acting complementary to other components, provides cytoskeleton with more flexibility and resistance to breaking [93, 94, 97]. In addition, vimentin is also often referred to for its regulatory role in cell mobility, proven in studies where its inhibition resulted in reduced cell migration [88, 92, 98, 99].

In this study, we developed a comprehensive approach to address the effects of a biomedical polymer with multi-scale topographical features on cell morphology and induction of conformational stress. The dimensions of the geometrical microscale surface features had distinct effects on cell cytoskeleton and nuclei. The ability to design materials that can subtly affect inner cell stiffness may be a refined approach to directing cell commitment into further differentiation stages.

\section{Conclusions and outlook}

This work has shown that $2 \mathrm{PP}$, a direct writing technique, coupled to an intermediate replication step is a valuable tool for high-resolution micropatterning of PLA, a widely used polymer for biomedical applications. The resolution and writing freedom offered by the $2 \mathrm{PP}$ technique are advantageous when compared to conventional lithography techniques for surface microstructuring, allowing the production of microsized features of multiple heights in the same sample within a single processing step. The embossing enables the high-resolution molding of PLA without prior chemical modification. Furthermore, the possibility of sample fabrication by molding increases the efficiency and throughput of sample production. While in this 
study PLA was used, the presented combination of techniques can also be applied to other (clinically) relevant thermoplastic polymers, including carriers of biomolecules, antibiotics and bioinorganics, and mechanically active/responsive polymers.

The analysis of the cross-talk between microstructural features of different shapes and dimensions and cell and nuclei shape and orientation and cytoskeleton organization has delivered useful input for the rational design of new instructive biomaterials. As such, this technical development has potential to advance the field of biomaterials, and more broadly, the field of regenerative medicine, further strengthening its multidisciplinary character.

\section{Acknowledgments}

DB gratefully acknowledges the financial support of the NIRM (Netherlands Institute of Regenerative Medicine). This research has been in part made possible with the support of the Dutch Province of Limburg $(\mathrm{PH})$.

\section{ORCID}

David Barata (ib https://orcid.org/0000-00028753-7403

\section{References}

[1] Van Blitterswijk C and De Boer J 2014 Tissue Engineering 2nd edn (Oxford: Elsevier) (https:/ / doi.org/10.1016/B978-0-12420145-3.00015-8)

[2] Gurtner G C, Callaghan M J and Longaker M T 2007 Progress and potential for regenerative medicine Annu. Rev. Med. 58 299-312

[3] McMurray R J, Dalby M J and Tsimbouri P M 2015 Using biomaterials to study stem cell mechanotransduction, growth and differentiation J. Tissue Eng. Regen. Med. 9528-39

[4] Chai C and Leong K W 2007 Biomaterials approach to expand and direct differentiation of stem cells Mol. Ther. 15 467-80

[5] Li L and Xie T 2005 Stem cell niche: structure and function Annu. Rev. Cell Dev. Biol. 21 605-31

[6] Subia B, Kundu J and Kundu S C 2010 Biomaterial Scaffold Fabrication Techniques for Potential Tissue Engineering Applications (Tissue Engineering) (Rijeka: InTech) ch 7 (https://doi.org/10.5772/8581)

[7] Khan F, Tanaka M and Ahmad S R 2015 Fabrication of polymeric biomaterials: a strategy for tissue engineering and medical devices J. Mater. Chem. B 3 8224-49

[8] Neves S C et al 2016 Additive manufactured polymeric 3D scaffolds with tailored surface topography influence mesenchymal stromal cells activity Biofabrication 8025012

[9] Jeon H, Lee H and Kim G 2014 A surface-modified poly (varepsilon-caprolactone) scaffold comprising variable nanosized surface-roughness using a plasma treatment Tissue Eng. C 20 951-63

[10] Mota $\mathrm{C}$ et al 2015 Additive manufacturing techniques for the production of tissue engineering constructs J. Tissue Eng. Regen. Med. 9 174-90

[11] Melchels F P W et al 2012 Additive manufacturing of tissues and organs Prog. Polym. Sci. 37 1079-104

[12] Malheiro A et al Direct writing electrospinning of scaffolds with multi-dimensional fiber architecture for hierarchical tissue engineering Frontiers Bioeng. Biotechnol. Conference
Abstract: 10th World Biomaterials Congress (https:/ / doi.org/ 10.3389/conf.FBIOE.2016.01.00755)

[13] Damanik F F R et al 2014 Towards an in vitro model mimicking the foreign body response: tailoring the surface properties of biomaterials to modulate extracellular matrix Sci. Rep. 46325

[14] Nandakumar A et al 2013 A fast process for imprinting micro and nano patterns on electrospun fiber meshes at physiological temperatures Small 93405

[15] Kolind Ket al 2012 Guidance of stem cell fate on 2D patterned surfaces Biomaterials 33 6626-33

[16] Moroni Let al 2015 Plug and play: combining materials and technologies to improve bone regenerative strategies J. Tissue Eng. Regen. Med. 9745-59

[17] Lee M R et al 2010 Direct differentiation of human embryonic stem cells into selective neurons on nanoscale ridge/groove pattern arrays Biomaterials 31 4360-6

[18] Yeh C W et al 2017 Development of biomimetic micropatterned device incorporated with neurotrophic gradient and supportive Schwann cells for the applications in neural tissue engineering Biofabrication 9015024

[19] Dalby M J, Gadegaard N and Oreffo R O C 2014 Harnessing nanotopography and integrin-matrix interactions to influence stem cell fate Nat. Mater. $13558-69$

[20] Wilkinson A et al 2011 Biomimetic microtopography to enhance osteogenesis in vitro Acta Biomater. $72919-25$

[21] Ahn E H et al 2014 Spatial control of adult stem cell fate using nanotopographic cues Biomaterials 35 2401-10

[22] Shi Z et al 2014 Enhanced endothelial differentiation of adipose-derived stem cells by substrate nanotopography J. Tissue Eng. Regen. Med. 8 50-8

[23] Nemeth C L et al 2014 Enhanced chondrogenic differentiation of dental pulp stem cells using nanopatterned PEG-GelMAHA hydrogels Tissue Eng. A 20 2817-29

[24] Wu Y-N et al Substrate topography determines the fate of chondrogenesis from human mesenchymal stem cells resulting in specific cartilage phenotype formation Nanomed.: Nanotechnol. Biol. Med. 10 1507-16

[25] Yim E K F, Pang S W and Leong K W 2007 Synthetic nanostructures inducing differentiation of human mesenchymal stem cells into neuronal lineage Exp. Cell Res. 313 1820-9

[26] Sung CY et al 2015 Probing neural cell behaviors through micro-/nano-patterned chitosan substrates Biofabrication 7 045007

[27] Koroleva A et al 2012 Two-photon polymerization-generated and micromolding-replicated 3D scaffolds for peripheral neural tissue engineering applications Biofabrication 4025005

[28] Marino A et al 2013 Two-photon polymerization of submicrometric patterned surfaces: investigation of cell-substrate interactions and improved differentiation of neuron-like cells ACS Appl. Mater. Interfaces 5 13012-21

[29] Weiß T etal 2011 Two-photon polymerization of biocompatible photopolymers for microstructured 3D biointerfaces Adv. Eng. Mater. 13 B264-73

[30] Kawata $S$ et al 2001 Finer features for functional microdevices Nature 412 697-8

[31] Haske W et al $200765 \mathrm{~nm}$ feature sizes using visible wavelength 3D multiphoton lithography Opt. Express 15 3426-36

[32] Felfel R M et al 2016 In vitro degradation and mechanical properties of PLA-PCL copolymer unit cell scaffolds generated by two-photon polymerization Biomed. Mater. 11015011

[33] Kapyla E et al 2014 Direct laser writing of synthetic poly(amino acid) hydrogels and poly(ethylene glycol) diacrylates by twophoton polymerization Mater. Sci. Eng. C 43 280-9

[34] Qin X-H et al 2014 Enzymatic synthesis of hyaluronic acid vinyl esters for two-photon microfabrication of biocompatible and biodegradable hydrogel constructs Polym. Chem. 5 6523-33

[35] Hendrikson W et al 2016 Mold-based application of laserinduced periodic surface structures (LIPSS) on biomaterials for nanoscale patterning Macromol. Biosci. 16 43-9 
[36] Dalby M J et al 2004 Investigating filopodia sensing using arrays of defined nano-pits down to $35 \mathrm{~nm}$ diameter in size Int. J. Biochem. Cell Biol. 36 2005-15

[37] Hulsman M et al 2015 Analysis of high-throughput screening reveals the effect of surface topographies on cellular morphology Acta Biomater. 15 29-38

[38] Danoux C et al 2016 Development of highly functional biomaterials by decoupling and recombining material properties Adv. Mater. 28 1803-8

[39] Koroleva A et al 2012 Fabrication of fibrin scaffolds with controlled microscale architecture by a two-photon polymerization-micromolding technique Biofabrication 4 015001

[40] Carpenter A E et al 2006 CellProfiler: image analysis software for identifying and quantifying cell phenotypes Genome Biol. 7 R100

[41] Lim J Y et al 2007 The regulation of integrin-mediated osteoblast focal adhesion and focal adhesion kinase expression by nanoscale topography Biomaterials 28 1787-97

[42] Mendonca Get al 2008 Advancing dental implant surface technology-from micron-to nanotopography Biomaterials 293822-35

[43] McNamara L E et al 2012 The role of microtopography in cellular mechanotransduction Biomaterials 33 2835-47

[44] Biggs M J and Dalby M J 2010 Focal adhesions in osteoneogenesis Proc. Inst. Mech. Eng. H 224 1441-53

[45] McBeath R et al 2004 Cell shape, cytoskeletal tension, and RhoA regulate stem cell lineage commitment Dev. Cell 6 483-95

[46] Tsimbouri P et al 2014 Nanotopographical effects on mesenchymal stem cell morphology and phenotype J. Cell Biochem. 115 380-90

[47] Engler A J et al 2006 Matrix elasticity directs stem cell lineage specification Cell 126 677-89

[48] Yang J et al 2014 Nanotopographical induction of osteogenesis through adhesion, bone morphogenic protein cosignaling, and regulation of MicroRNAs ACS Nano 8 9941-53

[49] Park J S et al 2011 The effect of matrix stiffness on the differentiation of mesenchymal stem cells in response to TGF$\beta$ Biomaterials 32 3921-30

[50] Rath B et al Compressive forces induce osteogenic gene expression in calvarial osteoblasts J. Biomech. 41 1095-103

[51] Mauney J R et al 2004 Mechanical stimulation promotes osteogenic differentiation of human bone marrow stromal cells on 3D partially demineralized bone scaffolds in vitro Calcif. Tissue Int. 74 458-68

[52] Delaine-Smith R M and Reilly G C 2012 Mesenchymal stem cell responses to mechanical stimuli Muscles Ligaments Tendons J. 2 169-80 (PMCID: PMC3666521)

[53] ArnsdorfE J et al 2009 Mechanically induced osteogenic differentiation-the role of RhoA, ROCKII and cytoskeletal dynamics J. Cell Sci. 122 546-53

[54] Sonam Set al 2016 Cell contractility arising from topography and shear flow determines human mesenchymal stem cell fate Sci. Rep. 620415

[55] Yang Y et al 2011 Engineering of a microfluidic cell culture platform embedded with nanoscale features Lab Chip 11 1638-46

[56] Kang K S et al 2011 Effects of combined mechanical stimulation on the proliferation and differentiation of preosteoblasts Exp. Mol. Med. 43 367-73

[57] Thompson W Ret al 2015 Osteocyte specific responses to soluble and mechanical stimuli in a stem cell derived culture model Sci. Rep. 511049

[58] Maul T M et al 2011 Mechanical stimuli differentially control stem cell behavior: morphology, proliferation, and differentiation Biomech. Model. Mechanobiol. 10 939-53

[59] Dalby M Jet al 2002 In vitro reaction of endothelial cells to polymer demixed nanotopography Biomaterials 23 2945-54

[60] McMurray R J et al 2011 Nanoscale surfaces for the long-term maintenance of mesenchymal stem cell phenotype and multipotency Nat. Mater. 10 637-44
[61] Dalby M J et al 2007 The control of human mesenchymal cell differentiation using nanoscale symmetry and disorder Nat. Mater. $6997-1003$

[62] Kingham E et al 2013 Nanotopographical cues augment mesenchymal differentiation of human embryonic stem cells Small 92140-51

[63] Cassidy J W et al 2014 Osteogenic lineage restriction by osteoprogenitors cultured on nanometric grooved surfaces: the role of focal adhesion maturation Acta Biomater. 10 651-60

[64] Dalby M J et al 2004 Rapid fibroblast adhesion to $27 \mathrm{~nm}$ high polymer demixed nano-topography Biomaterials 25 77-83

[65] Chen W et al 2012 Nanotopography influences adhesion, spreading, and self-renewal of human embryonic stem cells ACS Nano $64094-103$

[66] Biggs M J P et al 2008 Adhesion formation of primary human osteoblasts and the functional response of mesenchymal stem cells to $330 \mathrm{~nm}$ deep microgrooves J. R. Soc. Interface 5 1231-42

[67] Hart A et al 2007 Osteoprogenitor response to low-adhesion nanotopographies originally fabricated by electron beam lithography J. Mater. Sci. Mater. Med. 18 1211-8

[68] Unadkat H V et al 2011 An algorithm-based topographical biomaterials library to instruct cell fate Proc. Natl Acad. Sci. USA 108 16565-70

[69] Gupta M et al 2015 Adaptive rheology and ordering of cell cytoskeleton govern matrix rigidity sensing Nat. Commun. 67525

[70] Klein F et al 2011 Two-component polymer scaffolds for controlled three-dimensional cell culture Adv. Mater. 23 1341-5

[71] Reimer A et al 2016 Scalable topographies to support proliferation and Oct 4 expression by human induced pluripotent stem cells Sci. Rep. 618948

[72] Estévez M et al 2015 Adhesion and migration of cells responding to microtopography J. Biomed. Mater. Res. A 103 1659-68

[73] Gupta M etal 2015 Micropillar substrates: a tool for studying cell mechanobiology Methods Cell Biol. 125 289-308

[74] Ingber D E 2006 Cellular mechanotransduction: putting all the pieces together again FASEB J. 20 811-27

[75] Prager-Khoutorsky M et al 2011 Fibroblast polarization is a matrix-rigidity-dependent process controlled by focal adhesion mechanosensing Nat. Cell Biol. 13 1457-65

[76] Solon J et al 2007 Fibroblast adaptation and stiffness matching to soft elastic substrates Biophys. J. 93 4453-61

[77] Gupta M et al 2016 Single cell rigidity sensing: a complex relationship between focal adhesion dynamics and large-scale actin cytoskeleton remodeling Cell Adhes. Migr. 10 554-67

[78] Balaban N Q et al 2001 Force and focal adhesion assembly: a close relationship studied using elastic micropatterned substrates Nat. Cell Biol. 3 466-72

[79] del Rio A et al 2009 Stretching single talin rod molecules activates vinculin binding Science 323 638-41

[80] Choquet D, Felsenfeld D P and Sheetz M P 1997 Extracellular matrix rigidity causes strengthening of integrin-cytoskeleton linkages Cell 88 39-48

[81] Tzur Y B, Wilson K L and Gruenbaum Y 2006 SUN-domain proteins: 'Velcro' that links the nucleoskeleton to the cytoskeleton Nat. Rev. Mol. Cell Biol. 7 782-8

[82] Ostlund C et al 2009 Dynamics and molecular interactions of linker of nucleoskeleton and cytoskeleton (LINC) complex proteins J. Cell Sci. 122 4099-108

[83] Dahl K N et al 2004 The nuclear envelope lamina network has elasticity and a compressibility limit suggestive of a molecular shock absorber J. Cell Sci. 117 4779-86

[84] Dupont Set al 2011 Role of YAP/TAZ in mechanotransduction Nature 474 179-83

[85] Ingber D E 1993 Cellular tensegrity: defining new rules of biological design that govern the cytoskeleton J. Cell Sci. 104 613-27 (PMID: 8314865)

[86] Bhadriraju K and Hansen L K 2002 Extracellular matrix- and cytoskeleton-dependent changes in cell shape and stiffness Exp. Cell Res. 278 92-100 
[87] Wakatsuki T et al 2001 Effects of cytochalasin D and latrunculin B on mechanical properties of cells J. Cell Sci. 114 1025-36 (PMID: 11181185)

[88] Rathje L S et al 2014 Oncogenes induce a vimentin filament collapse mediated by HDAC6 that is linked to cell stiffness Proc. Natl Acad. Sci. USA 111 1515-20

[89] Eckes B et al 1998 Impaired mechanical stability, migration and contractile capacity in vimentin-deficient fibroblasts $\mathrm{J}$. Cell Sci. 111 1897-907 (PMID: 9625752)

[90] Helfand B T et al 2011 Vimentin organization modulates the formation of lamellipodia Mol. Biol. Cell 22 1274-89

[91] Hookway C et al 2015 Microtubule-dependent transport and dynamics of vimentin intermediate filaments Mol. Biol. Cell 26 1675-86

[92] Dave J M and Bayless K J 2014 Vimentin as an integral regulator of cell adhesion and endothelial sprouting Microcirculation $21333-44$
[93] Herrmann H et al 2009 Intermediate filaments: primary determinants of cell architecture and plasticity J. Clin. Invest. $1191772-83$

[94] Wagner O I et al 2007 Softness, strength and self-repair in intermediate filament networks Exp. Cell Res. 313 2228-35

[95] Murray M E, Mendez M G and Janmey P A 2014 Substrate stiffness regulates solubility of cellular vimentin Mol. Biol. Cell 25 87-94

[96] Guo M et al 2013 The role of vimentin intermediate filaments in cortical and cytoplasmic mechanics Biophys. J. 105 1562-8

[97] Shabbir S H et al 2014 Geometric control of vimentin intermediate filaments Biomaterials 35 1359-66

[98] Lepekhin E A et al 2001 Intermediate filaments regulate astrocyte motility J. Neurochem. 79 617-25

[99] Tezcan O and Gunduz U 2014 Vimentin silencing effect on invasive and migration characteristics of doxorubicin resistant MCF-7 cells Biomed Pharmacother. 68 357-64 